\title{
Cyclist's iliac syndrome: temporary relief by balloon angioplasty
}

\author{
L D Wijesinghe, P A Coughlin, I Robertson, D Kessel, P J Kent, R C Kester
}

\begin{abstract}
External iliac stenosis due to endofibrosis is a rare condition that predominantly affects top level cyclists. Short term symptomatic relief is reported in an Olympian after percutaneous transluminal angioplasty, which was performed to allow the patient to return to training without delay. (Br f Sports Med 2001;35:70-71)
\end{abstract}

Keywords: cycling; iliac syndrome; endofibrosis; arterial disease; claudication; angioplasty

Arterial disease in the young is extremely uncommon. However, young top level competition cyclists are at an increased risk of developing claudication-like symptoms of one lower limb at near maximal exercise. ${ }^{1}$ The cause of this is usually endofibrosis of the external iliac artery. ${ }^{1}$ This report addresses the case of an Olympic cyclist presenting shortly before the Atlanta games who required effective treatment with an almost immediate return to full activity.

\section{Case report}

A 28 year old female cyclist presented two weeks before the 26th Olympiad in Atlanta with right thigh and calf claudication brought on by maxi-

\section{Department of Vascular and Endovascular Surgery, St James's University Hospital, Leeds, UK L D Wijesinghe \\ P A Coughlin P J Kent \\ R C Kester}

Department of Interventional

Radiology

I Robertson

D Kessel

Correspondence to: Mr Wijesinghe, Department of Vascular Surgery, Leeds General Infirmary, Great George St, Leeds LS9 7TF, UK

ldw@yorvik.u-net.com

Accepted 25 October 2000 mal effort during training. All lower limb pulses were palpable, but the ankle brachial pressure

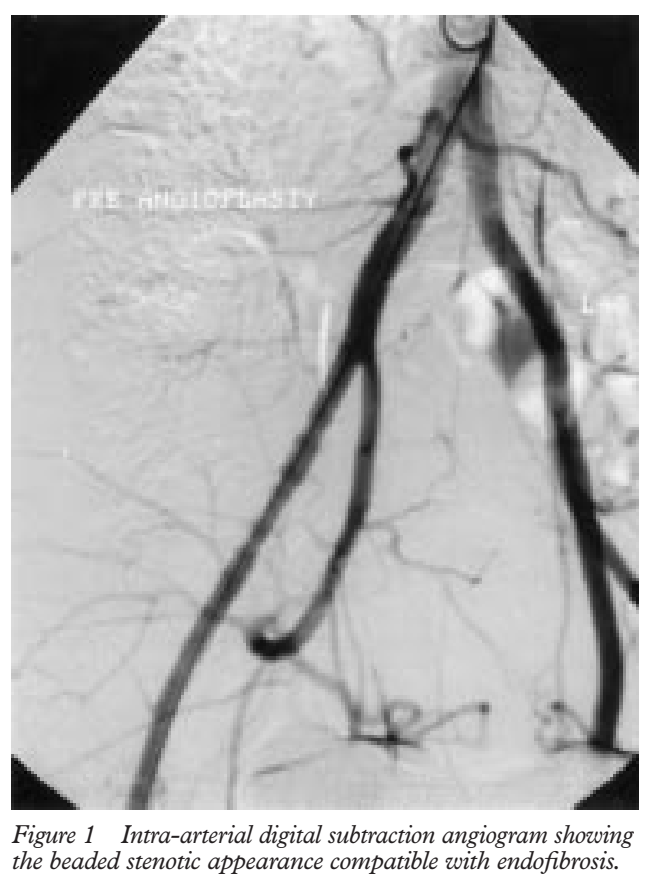

index in the right leg fell from 1.18 at rest to 0.55 immediately after vigorous cycling effort. A lower limb arterial duplex scan was performed which showed no evidence of a significant stenosis in the right external iliac artery. Intra-arterial digital subtraction angiography was then undertaken, with views in both the anteroposterior and left anterior oblique projections (fig 1). These confirmed the beaded stenotic appearance compatible with endofibrosis. Intra-arterial pressure gradients across the right external iliac artery were normal at rest but increased to $28 \mathrm{~mm} \mathrm{Hg}$ after vasodilatation with $25 \mathrm{mg}$ intra-arterial tolazoline. Proximity to the Olympic cycling heats would not permit surgical intervention without significant interruption to training. Therefore balloon angioplasty of the diseased segment was performed with a $7 \mathrm{~mm} \times$ $4 \mathrm{~mm}$ balloon inflated to 10 atmospheres for one minute. The film after angioplasty (fig 2 ) shows little change in vessel calibre, but there was symptomatic improvement without a fall in the ankle brachial pressure index after exercise.

The patient went on to compete in her event, free of pain, finishing half way down a field of 40 cyclists. Six weeks after the race her symptoms returned and she is considering definitive surgical treatment. 


\section{Discussion}

External iliac artery disease is well reported in performance cyclists and long distance runners. ${ }^{1-3}$ Pathological examination of arteries from affected people have found stenotic intimal thickening caused by moderately cellular loose connective tissue with a variable distribution of collagen and elastin fibres. ${ }^{4}$ This is thought to be brought about by a high flow arterial state in this arterial segment secondary to the anatomical conditions experienced by cyclists in their attempts to maintain an aerodynamic position on the bike.

These structural changes in the external iliac artery result in the development of a subcritical stenosis, the effects of which are unmasked by the high flow rates demanded during strenuous exercise.

Duplex characteristically shows both enhanced echogenicity of the arterial wall and a mild narrowing of the arterial diameter of the diseased external iliac artery. ${ }^{1}$ Arteriography typically shows lengthening of the diseased artery with a mild to moderate stenosis. ${ }^{4}$

Surgical treatment of such lesions is successful and remains the management of choice in cyclist's iliac syndrome. A reported series of 23 cases describes successful treatment by segmental resection, endarterectomy, and ligation of the psoas branch of the external iliac artery. ${ }^{4}$ More recently, it has been suggested that the long term evolution of this condition is one of stabilisation on the conclusion of intensive training and that surgery should only be offered to allow affected subjects to continue in competition. $^{5}$

Surgery was not a viable option in our patient who wanted to return to training without delay. Therefore percutaneous transluminal angioplasty was undertaken with good clinical results. This case illustrates the short term benefit of angioplasty in cyclist's iliac syndrome when surgery needs to be avoided or postponed. However, its role in the long term management is still debatable.

1 Abraham P, Saumet JL, Chevalier JM. External iliac artery endofibrosis in athletes. Sports Med 1997;24:221-6.

2 Chevalier JM, Enon B, Walder J, et al. Endofibrosis of the external iliac artery in bicycle racers: an unrecognized pathological state. Ann Vasc Surg 1986;1:297-303.

3 Wright IA, Pugh ND, Goodfellow J, et al. Dynamic obstruction of the external iliac artery in endurance athletes and its relationship to endothelial function: the case of a long distance runner. Br 7 Sports Med 1997;31:156-8.

4 Rousselet MC, Saint-Andre JP, L'Hoste P, et al. Stenotic intimal thickening of the external iliac artery in competition cyclists. Hum Pathol 1990;21:524-9.

5 Abraham P, Chevalier JM, Saumet JL. External iliac artery endofibrosis: a 40-year course. I Sports Med Phys Fitness 1997;37:297-300.

\section{Take home message}

- Competitive cyclists are at risk of developing cyclist's iliac syndrome

- Balloon angioplasty may achieve temporary relief of symptoms and avoids the risks of surgical bypass

\section{Commentary}

I have to declare an interest when refereeing this paper. The circumstances and the athlete involved are well known to me as I was the medical officer to the GB cycling team at these Olympic Games.

The severity of symptoms and their close proximity to the Games were such that, had the cyclist taken part without treatment, it would have amounted to participation rather than to competition. Some clinicians may object to this operative intervention on a short term basis, but most sports doctors would support the view that it can be justified on the "once in a lifetime" opportunity it gave the athlete.

It is only within the last five years that any level of awareness of external iliac artery syndrome has reached the wider sports medicine community - all this in spite of the earliest reference cited dating back to 1986 and a previous British fournal of Sports Medicine paper that described the surgical treatment of the first case that I am aware of in the United Kingdom. I was originally alerted to the condition by a sports journalist who had noted that a number of European professionals had undergone vascular surgery and was wondering whether this constituted some as yet unbanned surgical doping technique!

The mechanism of external iliac artery syndrome is as yet unknown and theories are little more than speculation. Trauma has been suggested as a cause; however, there can be no elite cyclist who is unable to provide a history of previous significant crashes. The aerodynamic crouched positions now adopted by cyclists have also been cited, and I should mention here that many of such positions have now been banned by the UCI on the grounds that they are too aerodynamic. In attempting to define the cause, it may be more constructive to think in terms of the athlete's position on the cycle, the repetitive flexion/extension movement at the thigh, and the vast number of hours spent in training and competition by elite cyclists. Given that this elite group will be cycling with a cadence of about 100 revolutions/minute for an average of four hours a day, six days a week for 50 weeks of the year, it follows that flexion/extension at the thigh is occurring in excess of 7 million times a year. Add to this a "compressed" position on the cycle and an otherwise inconsequential anomaly of the external iliac vessels, and the syndrome may just be produced. 